\title{
Stretch Reflex Latencies in Spastic Hemiparetic Subjects are Prolonged After Transcutaneous Electrical Nerve Stimulation
}

\author{
Christina W.Y. Hui-Chan and Mindy F. Levin
}

\begin{abstract}
Low-intensity repetitive electrical stimulation such as dorsal column and transcutaneous electrical nerve stimulation (TENS) reportedly decreases spasticity and improves voluntary motor control. However, the mechanisms mediating these effects are unclear. Recent findings suggest that spasticity may be characterized more appropriately by a decrease in the stretch reflex threshold than by an increase in gain. Our objectives were: (1) to examine possible changes in stretch reflex excitability following $45 \mathrm{~min}$ of TENS, (2) to map out the time course of possible post-stimulation effects via both latency and magnitude (amplitude or area) measurements, and (3) to determine the role of segmental versus non-segmental mechanisms involved in mediating these changes. The effects of 45 min of segmentally and heterosegmentally applied TENS on lower limb reflexes in ten spastic hemiparetic subjects were contrasted with those resulting from placebo stimulation. We found that both segmentally and heterosegmentally applied TENS caused an immediate increase in soleus $H$ reflex latencies that was evident for up to 60 minutes post-stimulation in over $75 \%$ of the subjects. Similar increases for up to 60 and 40 minutes post-stimulation was noted for the stretch reflex latencies in $50 \%$ and $67 \%$ of the subjects respectively for segmental and heterosegmental stimulation. These results suggested that manipulation of segmental and heterosegmental afferents for 45 min may lead to a decrease of the otherwise augmented stretch reflex excitability accompanying hemiparetic spasticity.
\end{abstract}

RÉSUMÉ: Latence prolongée du reflexe myotatique chez les sujets hémiparétiques spastiques après stimulation nerveuse électrique transcutanée. Selon la littérature, une stimulation électrique répétitive de faible intensité, telle la stimulation nerveuse électrique de la colonne vertébrale et la stimulation transcutanée, diminue la spasticité et améliore le contrôle moteur volontaire. Cependant, les mécanismes sous-jacents sont peu connus. Des données récentes suggèrent que la spasticité serait mieux définie par un abaissement du seuil du réflexe myotatique que par une augmentation du gain. Les objectifs de notre étude étaient les suivants: 1) d'examiner s'il existe des changements dans l'excitabilité du réflexe myotatique après 45 minutes de TENS; 2 ) de documenter l'évolution dans le temps d'effets posi-stimulation possibles par des mesures de latence et de grandeur (amplitude ou surface); 3 ) de préciser le rôle des mécanismes segmentaires versus non-segmentaires impliqués dans la médiation de ces changements. Les effets d'une application de TENS de 45 minutes de façon segmentaire et hétérosegmentaire sur les réflexes des membres inférieurs chez 10 sujets hémiparétiques ont été comparés à ceux résultant d'une stimulation placebo. Nous avons constaté que l'application segmentaire et hétérosegmentaire de TENS provoque une augmentation immédiate des latences du réflexe H soléaire qui était évidente jusqu'à 60 minutes post-stimulation chez plus de $75 \%$ des sujets. Des augmentitions de latence du réflexe myotatique d'une durée de 60 et 40 minutes post-stimulation ont été notées chez 50 et $67 \%$ des sujets respectivement pour la stimulation hétérosegmentaire. Ces résultats suggèrent que la manipulation des afférents segmentaires et hétérosegmentaires pendant 45 minutes peut induire une diminution de l'excitabilité du réflexe myotatique qui est augmentée dans la spasticité hémiparétique.

Can.J. Newrol. Sci. 1993: 20:97-106

According to the traditional view, spasticity is due to hyperactivity of the stretch reflex arc manifested by a velocity-dependent increase in tonic and phasic stretch reflexes, sometimes accompanied by clonus. ${ }^{1}$ Hyperactivity in this arc could result from either abnormal segmental afferent input to proprioceptive reflex circuits in the spinal cord, or from abnormal processing of otherwise normal input from the periphery, or both. However, findings from a primate model of hemiplegia $a^{2}$ and from patients $s^{3.4}$ both suggest that afferent input to the spinal cord is essentially unaltered in spasticity. On the other hand, an increase in the average resting membrane potential of $\alpha$ motoncurons. caused by a net increase in descending excitation, could result in

From the School of Physical and Occupational Therapy, Faculty of Medicine, McGill University, Montreal

Received October 15, 1991. Accepted in final form November 25, 1992

Reprint requests to: Dr. Christina W.Y. Hui-Chan, School of Physical and Occupational Therapy, Faculty of Medicine, McGill University, 3654 Drummond Street, Montreal, Quebec, Canada H3G IY5 
an earlier activation of motoneurons. ${ }^{5.6}$ This could lead to a decrease in stretch reflex threshold and the enhanced reflex activity reported in spasticity. ${ }^{7.8}$

Another principal sign of spasticity is irradiation of reflexes..$^{910}$ Consequently, remote or heterosegmental afferents may play an important role as evidenced by the reductions in spasticity following techniques such as peripheral nerve blocks" and repetitive electrical stimulation of agonist ${ }^{12}$ or antagonist muscles. ${ }^{13-16}$ Similarly, large diameter afferent conditioning via dorsal column stimulation (DCS) has been found to decrease spasticity, although the underlying mechanisms have not been elucidated. ${ }^{17.18}$

While DCS requires surgical exposure of the spinal cord, an alternative technique, transcutaneous electrical nerve stimulation (TENS), is non-invasive. Low intensity, high frequency TENS is thought to predominantly activate large diameter afferents in the $A \alpha B$ range. ${ }^{19}$ It is noteworthy that in a clinical study of 49 multiple sclerosis patients, two weeks of continuous TENS or DCS applied heterosegmentally was found 10 produce a significant improvement in bladder function. This was associated with an improvement in the motor performance of knee flexors and extensors in the patients tested $(n=18 \text { or } 27)^{20}$ More recently, we showed that 15 daily $60 \mathrm{~min}$ TENS treatments applied segmentally over a three-week period decreased clinical spasticity, improved reflex functions of spastic plantarflexors and improved voluntary control of paretic dorsiflexors in hemiparetic subjects. ${ }^{21}$ In other words, repetitive afferent conditioning via either DCS or TENS has been shown to decrease spasticity and improve reflex and voluntary motor functions.

While the underlying mechanisms remain unclear, an interesting observation is that very brief (several seconds of) DCS could have prolonged effects (up to minutes), which cannot be explained solely by simple synaptic mechanisms. For example, in decerebrate cats, Chapman et al. ${ }^{22}$ found that the suppression of static but not dynamic stretch reflexes outlasted the period of DCS (1-10 min) for 5 to $20 \mathrm{~min}$. In three spastic patients, Siegfried et al. ${ }^{23}$ reported an elevation of $\mathrm{H}$ reflex thresholds for up to $3 \mathrm{~min}$ following only one $300 \mathrm{~ms}$ conditioning train applied to the dorsal column. Indeed, longer applications of TENS may have even more prolonged effects. For example, Chan and Tsang ${ }^{24}$ found long-lasting inhibition of the lower limb flexion reflex in normal subjects, in some cases for more than one hour, following $30 \mathrm{~min}$ of low-intensity TENS applied segmentally to the low back. The prolonged inhibition of flexion reflexes has been attributed to the release of opioids. ${ }^{25}$ These findings open up the possibility that TENS may also generate prolonged depression of stretch reflex excitability.

In an earlier study, we investigated the immediate effects of 30 min of segmentally applied TENS on the reflex measures of the spastic soleus muscle in hemiparetic patients. ${ }^{8}$ TENS applied to the low back of these patients produced no significant change in the amplitude of $\mathrm{H}$ and stretch reflexes. However, the extent to which reflex amplitudes or gains reflect the severity of spasticity has lately been questioned. Investigating stretch reflex activity in the spastic elbow flexors of hemiparetic subjects during background contractions, Lee et al. ${ }^{26}$ and Powers et al. ${ }^{27}$ suggested that spasticity may be characterized more appropriately by a decrease in the stretch reflex threshold than by an increase in gain. In these studies, a reduced threshold was implied by the appearance of EMG activity after a smaller elbow joint deflection, while stretch reflex gain or stiffness in the majority of these patients was not found to be significantly different from the non-affected limb or from normal subjects, at least in voluntarily activated spastic muscle.

Since threshold changes may be reflected in appropriate latency changes, we re-examined the immediate effects of 45 min of TENS (versus $30 \mathrm{~min}$ in the previous study ${ }^{8}$ ) on the latency and magnitude characteristics of both the predominantly monosynaptic and polysynaptic stretch reflexes in the spastic calf muscles of hemiparetic patients. Furthermore, the time course of possible post-stimulation effects was determined by repeating the measurements of stretch reflex excitability at 20 min intervals for up to $60 \mathrm{~min}$ after the cessation of TENS. Finally, to delineate the respective contribution of segmental versus non-segmental (e.g., propriospinal and descending) mechanisms, the effects of segmentally applied TENS on stretch reflex excitability were contrasted with heterosegmental and placebo stimulation. Some of these data have previously appeared in abstract form. ${ }^{28}$

\section{Methods and Materials}

\section{Subjects}

Ten patients with unilateral spastic hemiparesis (mean $=56.2$ \pm S.D. 13.5 years), of either cerebrovascular ( 9 subjects) or traumatic ( 1 subject) origin, participated voluntarily in the study. All the subjects had spasticity in the lower extremity, a minimum of $10^{\circ}$ of passive ankle dorsiflexion, no history of a previous stroke or other neurological disorder, no pain in the lower extremity, no major sensory impairment, and were ambulatory. Eight of the subjects were taking anti-hypertensive medication. Only one subject (\#10 in Table 1) was on a regular schedule of the antispastic drug, dantrolene sodium, during the study. His testing sessions were scheduled at the same time each day to avoid any fluctuations in results due to the presence or absence of the medication. Subjects were advised as to the nature of their participation and gave their informed consent. Table I summarizes the demographic data for these hemiparetic subjects.

The assessment of spasticity was done by the same investigator with subjects comfortably seated. It was evaluated on the affected side but not the contralateral side which displayed essentially normal tone. There were altogether three clinical measurements: 1) Achilles tendon jerks were scored using the usual 5-point scale, were " 0 " denoted "no response" and " 4 " indicated "maximally hyperactive response". 2) Resistance to full-range passive ankle dorsiflexion at a moderate speed was evaluated with a modified 5-point Ashworth Scale. ${ }^{29}$ Since this measurement most closely represents "tone", 30 it was doubly weighted so that a score of " 8 " corresponded to "maximally increased resistance". 3) Clonus was assessed with a 4-point scale, where " $l$ " indicated "clonus not elicited" and " 4 " represented "sustained clonus". This evaluation was carried out to provide a composite (albeit subjective) index of spasticity. Based on our clinical experience, the computed "spasticity scores" ranging from 0 to 9,10 to 12 and 13 to 16 corresponded to "mild", "moderate", and "severe" spasticity respectively (Table 1).

\section{Experimental and Stimulation Protocol}

Subjects participated in three testing sessions on three different days, spaced at least one week apart. In each session, they 
Table 1. Clinical Features of and Reflex Measurements in Spastic Hemiparetic Subjects

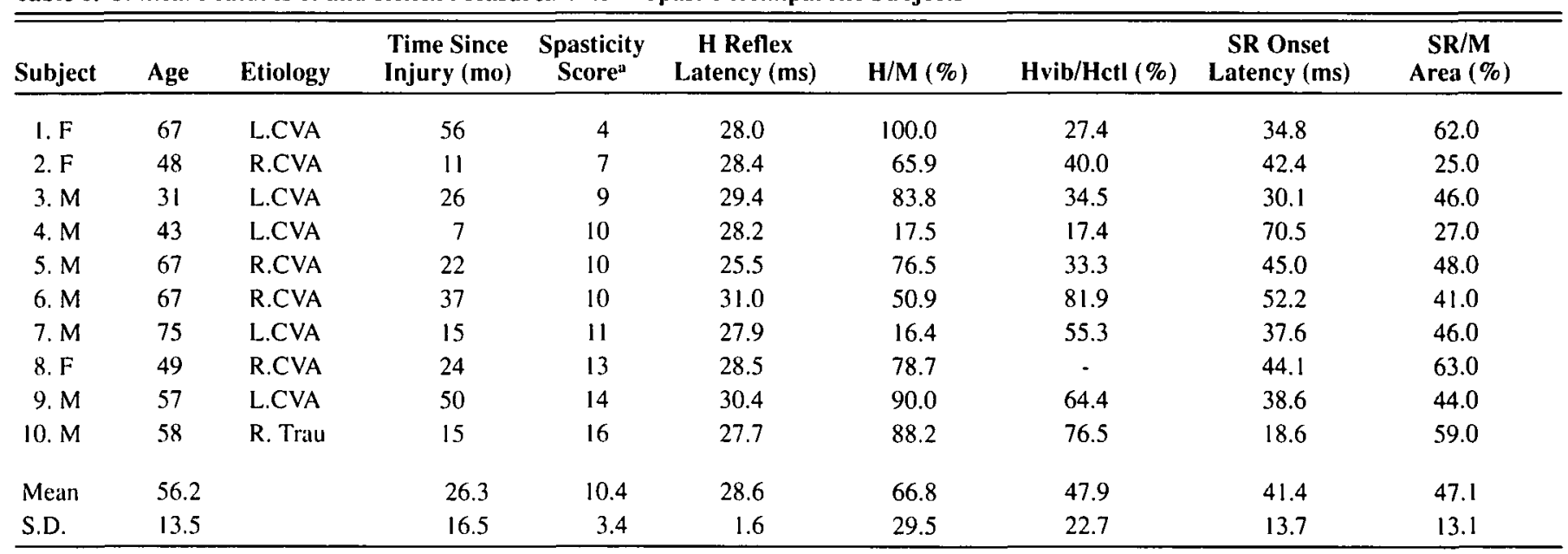

"The spasticity score is based on three clinical measures of spasticity:

1) Achilles tendon reflex

2) resistance to passive stretch

3) clonus

Scores ranging from $0-9,10-12$ and $13-16$ respectively were classified as mild, moderate and severe spasticity.

$\mathrm{F} / \mathrm{M} \quad=$ female/male

L./R. CVA $=$ left/right cerebrovascular accident

Trau $\quad=$ Trauma

received either $45 \mathrm{~min}$ of 1) segmentally or 2) heterosegmentally applied TENS, or 3) placebo stimulation, as described below. The order of the testing sessions was randomized.

TENS and placebo stimulation were applied via a Selectra 7720 stimulator (Medtronic) for a period of $45 \mathrm{~min}$ through two rectangular rubber surface electrodes $(3.8 \mathrm{~cm} \times 5.1 \mathrm{~cm})$ attached to the skin. Stimulation consisted of continuous high-frequency (99 Hz), square $0.125 \mathrm{~ms}$ electrical impulses delivered at low intensity (twice the sensory threshold) for TENS, and at essentially zero intensity $(0.1 \times$ threshold) for placebo stimulation. At the beginning of each testing session, sensory threshold was determined by gradually increasing the intensity of the stimulation to a level when the subject first reported a faint tingling sensation. The intensity was then decreased until no sensation was felt. The average of three such trials was used to determine the threshold intensity for each session. The sub-threshold intensity TENS was considered "placebo" stimulation, since subjects were instructed that they may or may not feel any sensation associated with the stimulation.

TENS was applied to two sites: 1) the common peroneal nerve (L4-S2) located just posterior to the head of the fibula, which supplies the muscles antagonistic to the spastic calf muscles; or 2) the volar aspect of the contralateral wrist over the median nerve (C6-Tl). The two sites were chosen in order to determine the differential effects of segmental versus heterosegmental mechanisms in the possible modification of stretch reflex excitability in spastic hemiparesis. Placebo stimulation was applied only to the first site.

Pre- and post-stimulation test batteries consisted of the clinical evaluation as described above and three physiological reflex measures. The latter involved recording the: 1) maximal amplitude of the $\mathrm{H}$ reflex as a percentage of the maximal $M$ response, termed here the $\mathrm{H} / \mathrm{M}$ ratio, ${ }^{31.32}$ 2) the amount of inhibition of the
$H$ reflex during vibration, expressed as a percentage of the control $\mathrm{H}$ reflex amplitude (Hvib/Hctl, see $^{33}$ for review); and 3 ) the excitability of the soleus stretch reflex (SR) in terms of latency, duration and magnitude (SR/M area). To further assess the time course of the post-stimulation effects, measurements were repeated at three $20 \mathrm{~min}$ intervals after the cessation of TENS or placebo stimulation.

\section{Reflex Testing Procedures}

For reflex testing, subjects reclined in a semi-supine position with the knee fixated at $30^{\circ}$ flexion and the ankle supported in the neutral position. This was done to ensure a constant initial length of the ankle muscles across all subjects, which had been shown to affect $\mathrm{H}$ reflex amplitude. ${ }^{34}$ The axis of rotation of the footplate, according to drawn anatomical landmarks, ${ }^{35}$ was aligned with that of the ankle joint. Ankle joint angles were monitored and recorded with a custom made electrogoniometer (Beckman 5311 potentiometer, R5K L.5) mounted on the same axis.

$\boldsymbol{H}$ reflex $\mathrm{H}$ reflexes were elicited by single $1.0 \mathrm{~ms}$ pulses, delivered at $0.1 \mathrm{~Hz}$ via a cathode (a $2 \mathrm{~cm}$ Medi-Trace FC-26 surface electrode) placed on the skin overlying the posterior tibial nerve in the popliteal fossa. The anode (a $20 \mathrm{~cm}^{2}$ tin plate) was positioned superior to the patella for selective stimulation of the nerve trunk. ${ }^{36}$ For each stimulus intensity investigated, 10 consecutive responses were collected and averaged on-line by a laboratory developed program written for the PDP 11-23 plus computer. The intensity of the stimulation was gradually increased to record maximal $H$ reflexes, termed here " $H$ ", followed by maximal $M$ responses ("M" or Mmax). The intensity was then decreased to register control $\mathrm{H}$ reflexes $(\mathrm{Hctl})$, which were set at approximately $30 \%$ of the Mmax across all subjects. This procedure ensured that similar motoneuronal pools were being activated by the 
stimulation, and that both increases and decreases in the excitability of the $\mathrm{H}$ reflex could be observed under standardized conditions. ${ }^{37}$

Vibration We tested the effects of vibrating the Achilles tendon at $100 \mathrm{~Hz}$, with a $2 \mathrm{~mm}$ peak-to-peak amplitude, on the $\mathrm{H}$ reflex amplitude. According to Desmedt and Godaux, ${ }^{33}$ these vibration parameters produce maximal inhibitory effects on the soleus $\mathrm{H}$ reflex. A vibrator (Ling Dynamics 101) was applied at a right angle to the skin overlying the inferior third of the Achilles tendon. Following a one-minute accommodation period, $10 \mathrm{H}$ reflexes (Hvib) were elicited and collected on-line, while the vibration was continued. After the cessation of vibration, $\mathrm{H}$ reflexes were monitored until they returned to at least $90 \%$ of the control value, before continuing with the experiment.

Stretch Reflexes To assess stretch reflex activity evoked in the soleus, the ankle was rapidly dorsiflexed by a mechanical stretching device, at a velocity of some $360^{\circ} / \mathrm{sec}$, through a ramp of $30^{\circ}$. Since the displacement parameters are likely critical in determining the latency of the stretch reflex, the reproducibility of the initial velocity (i.e., the slope of the displacement trace during the first $30 \mathrm{~ms}$ of stretch), maximal velocity and maximal displacement were assessed across subjects and no statistical differences were found $(p>0.10, p>0.10, p>0.05)$. Subjects were instructed not to voluntarily intervene during the ankle perturbation. The mechanical stretching device consisted of a footplate attached to an overhead bar by $50 \mathrm{lb}$ springs, and a mechanical stop which arrested ankle dorsiflexing movement at $10^{\circ}$ past the neutral position of the joint. To evoke the stretch reflex, the footplate and ankle were manually displaced to $20^{\circ}$ plantarflexion past the neutral position and maintained for 10 sec. During this time, soleus and tibialis anterior EMG were monitored on the oscilloscope, to ensure that the background EMG was sufficiently quiet. The computer data collection program was triggered $500 \mathrm{~ms}$ prior to the release of the footplate, in order to have adequate baseline EMG for subsequent analysis. To allow sufficient recovery in the reflex pathways, at least $30 \mathrm{sec}$ of rest was given between trials.

\section{EMG Recording}

After careful preparation of the skin, disposable silver-silver chloride surface electrodes (Medi-Trace 1801) were positioned on the soleus and tibialis anterior muscles of the affected leg. For soleus EMG, the electrodes were placed $3 \mathrm{~cm}$ apart, $4 \mathrm{~cm}$ below the intersection of the medial and lateral heads of gastrocnemius and the Achilles tendon. ${ }^{36}$ For tibialis anterior EMG, the electrodes were oriented longitudinally along the muscle bulk, 3 $\mathrm{cm}$ apart, $7 \mathrm{~cm}$ below and $5 \mathrm{~cm}$ lateral to the antero-superior border of the tibia. A common reference electrode was positioned over the head of the fibula. Soleus and tibialis anterior EMG signals were amplified with a gain of 1,000 for $\mathrm{H}$ reflex and of 5,000 for stretch reflex trials, and filtered $(10$ to $500 \mathrm{~Hz})$ by Disa $15 \mathrm{CO} 1$ amplifiers. They were then monitored on a storage oscilloscope (Textronix R5115) before being digitized at 2,000 and $1,250 \mathrm{~Hz}$ respectively for $\mathrm{H}$ and stretch reflexes, and stored in a PDP11-23 plus microprocessor. Soleus EMG activity was recorded for $200 \mathrm{~ms}$ following the $\mathrm{H}$ reflex stimulation. EMG activity from the soleus and tibialis anterior muscles, as well as the ankle displacement, were recorded for up to $900 \mathrm{~ms}$ following the stretch perturbation.

\section{Data Analysis}

$\boldsymbol{H}$ reflexes and $\boldsymbol{M}$ responses Individual and mean peak-topeak $H$ reflex and $M$ response amplitude values were calculated on-line. Maximal $M$ response areas were computed off-line by rectifying and integrating the $M$ wave within a window determined from the response onset to its offset (the point at which the trace exceeded, or returned to, 3 S.D. of the baseline). Since EMG values can vary according to skin preparation and electrode placement in the same subject on different days, a means of normalizing EMG amplitude and area values was sought. The maximal $M$ response is presumed to represent the total motoneuronal pool activated by a maximal stimulus. ${ }^{32,38}$ EMG amplitude and/or area values were therefore expressed as ratios of the appropriate parameter of the maximal $M$ response (i.e., $\mathrm{H} / \mathrm{M}$ amplitude; $\mathrm{SR} / \mathrm{M}$ area). The amplitude of the $\mathrm{H}$ reflex during vibration was calculated as a percentage of the control $\mathrm{H}$ reflex amplitude (Hvib/Hctl). These normalization procedures were done so that mean values could be compared across subjects (see Statistical Analysis).

Stretch Reflexes Individual stretch reflex trials were analyzed off-line for latency, response duration, and area. Trials were screened qualitatively prior to inclusion in the analysis, to eliminate those in which the subject intervened voluntarily or was unable to relax completely. EMG signals were rectified and background baseline activity removed. EMG latency was determined from the onset of displacement (i.e., when the displacement surpassed $2^{\circ}$ or approximately $7 \%$ of total displacement), to the time when the EMG signal exceeded 3 S.D. of the baseline value. The duration of the stretch reflex was calculated from the EMG onset to the time when the EMG returned to 3 S.D. from the baseline. Finally, soleus and tibialis anterior EMG areas (when the latter were present) were calculated by a computer algorithm that determined the maximal integral of the EMG over the $150 \mathrm{~ms}$ following its onset. These were expressed as percentages of the maximal $M$ response areas evoked in the same muscles.

\section{Statistical Analysis}

For some analyses, $\mathrm{H}$ reflex latencies, $\mathrm{H} / \mathrm{M}$ and $\mathrm{Hvib} / \mathrm{Hctl}$ ratios, as well as parameters of the stretch reflex were expressed as percentages of their corresponding pre-stimulation control values for each subject. After determining homogeneity of variances in the three groups, changes of these measurements in each 20 min post-stimulation time interval were compared between TENS and placebo treatments. Raw $\mathrm{H}$ and stretch reflex latency values in each post-stimulation time period were also compared to pre-test control values. Occasionally, data in the three post-stimulation time intervals were pooled. Repeated measures or completely randomized ANOVAs compared the effects of the segmental and heterosegmental TENS stimulation with placebo treatments on each reflex measure. A significance level of 0.05 was used for all two-tailed tests.

\section{RESULTS}

\section{Characteristics of Reflex Responses}

Consistent with previous reports (e.g., Ashby and Verrier ${ }^{7}$ ), $\mathrm{H} / \mathrm{M}$ ratios were greater in our spastic hemiparetic subjects $(\mathrm{n}=10 ; 66.8 \pm$ S.D. $29.5 \%)$ than normal age-matched control subjects $(n=7 ; 42.2 \pm 17 \% \mathrm{p}<0.05) .{ }^{39}$ Examples of $\mathrm{H} / \mathrm{M}$ and 
$\mathrm{Hvib} / \mathrm{Hctl}$ ratios for two subjects are illustrated in Figure 1. The subject shown in Figure I (A - C) was a 48-year-old female with left hemiparesis and mild spasticity. She had an H/M ratio of $65.9 \%$ and an $\mathrm{Hvib} / \mathrm{Hctl}$ ratio of $40.0 \%$. In contrast, the subject in Figure 1 (D - F) was a 57-year-old male with right hemiparesis and severe spasticity, who had an $\mathrm{H} / \mathrm{M}$ ratio of $90 . \%$ and an $\mathrm{Hvib} / \mathrm{Hctl}$ ratio of $64.4 \%$. $\mathrm{H} / \mathrm{M}$ and $\mathrm{Hvib} / \mathrm{Hctl}$ ratios for each subject relative to his spasticity score prior to TENS are shown in Table 1. Correlations between $\mathrm{H}$ and stretch reflex measurements and spasticity scores revealed only poor relationships. ${ }^{39}$ For example, weak correlations were found between the total spasticity score and $\mathrm{H} / \mathrm{M}$ ratios $(r=0.27)$, Hvib/Hctl ratios $(r=0.43), H$ reflex latencies $(r=0.32), S R / M$ ratios $(r=0.55)$ and SR latencies $(r=-0.41)$. As expected, there was a significant correlation between $\mathrm{H}$ and stretch reflex magnitudes $(r=0.76, p<0.05)$, but $H$ and stretch reflex latencies were not related $(r=0.13)$.

\section{Effects of TENS on $H$ Reflexes}

Mean control $H$ reflex latencies, recorded before the three stimulation procedures, did not differ from each other. These values, obtained prior to TENS stimulation to the leg, to the wrist, or to placebo stimulation, were $28.6 \pm 1.6 \mathrm{~ms}, 28.8 \pm 2.1$ $\mathrm{ms}$ and $29.7 \pm 2.3 \mathrm{~ms}$ respectively. Their reproducibility over different testing sessions was thus evident. In contrast to placebo stimulation which had no effect on the $\mathrm{H}$ reflex latencies (mean post-placebo latency was $29.5 \pm 2.2 \mathrm{~ms}$ ), TENS stimulation to the leg prolonged the latency by a mean of $1.7 \mathrm{~ms}(\mathrm{Pl}=$ $30.7 \pm 1.7 \mathrm{~ms} ; \mathrm{P} 2=30.8 \pm 2.4 \mathrm{~ms} ; \mathrm{P} 3=30.6 \pm 2.4 \mathrm{~ms}$; overall mean $=30.3 \pm 2.3 \mathrm{~ms}$ ). TENS to the wrist prolonged the latency by a mean of $2.2 \mathrm{~ms}(\mathrm{Pl}=29.8 \pm 3.4 \mathrm{~ms} ; \mathrm{P} 2=30.5 \pm 4.1 \mathrm{~ms}$; $\mathrm{P} 3=31.1 \pm 4.7 \mathrm{~ms}$; overall mean $=31.0 \pm 3.6 \mathrm{~ms}$ ).

Due to the large inter-subject variability of $\mathrm{H}$ reflex measures, the post-stimulation values were expressed as percentages of the subjects' own control values, in order to compare the results of each treatment across subjects. Figure 2 shows the group mean (+ S.D.) changes in $\mathrm{H}$ reflex latencies, $\mathrm{H} / \mathrm{M}$ and $\mathrm{Hvib} / \mathrm{Hctl}$ ratios in the three $20 \mathrm{~min}$ post-stimulation time intervals (PI, P2, P3) after TENS application to the leg (filled bars), or to the wrist (hatched bars), and after placebo stimulation to the leg (open bars). Placebo stimulation had no effect on $\mathrm{H}$ reflex latencies in the hemiparetic subjects (mean change of the three post-stimulus intervals was $99.7 \pm 8.3 \%$ ). In contrast, Figure 2 (left panel) shows that segmental and heterosegmental TENS produced a significant increase in $\mathrm{H}$ reflex latencies which was evident in each of the 20 min time intervals following TENS. The mean post-stimulus change in latency, averaged over the three time periods, was $106.5 \pm 8.7 \%(\mathrm{p}<0.02)$ following TENS to the leg, and $105.7 \pm 6.2 \%(p=0.02)$ following TENS to the wrist.

\section{Effects of TENS on Stretch Reflexes}

While TENS stimulation prolonged $\mathrm{H}$ reflex latencies in over $75 \%$ of the subjects (see Figure $5 \mathrm{~A}$ ), stretch reflex latencies were increased in only $50 \%$ to $67 \%$ of the subjects examined. Comparing post-stimulation to pre-stimulation values, stretch reflex latencies increased by a mean value of $6.4 \pm 3.0 \mathrm{~ms}$ in 5 of the 10 subjects following TENS to the leg, and by $5.0 \pm 2.7$ $\mathrm{ms}$ in 4 of the 6 subjects following TENS to the wrist (Table 2). In contrast, placebo stimulation either had no effect or decreased these latencies. The mean value in the placebo group was $45.5 \pm$ $11.7 \mathrm{~ms}$ before stimulation and $39.7 \pm 10.2 \mathrm{~ms}, 37.6 \pm 12.6 \mathrm{~ms}$, and $42.6 \pm 13.7 \mathrm{~ms}$ respectively in the three post-stimulation time periods.

An example of the effect of TENS on the soleus stretch reflex latency is shown in Figure 3A - D for one subject with moderate spasticity. The mean values of ten stretch reflexes (solid lines) are displayed on the same time scale along with the corresponding mean ankle displacement (dashed lines) before

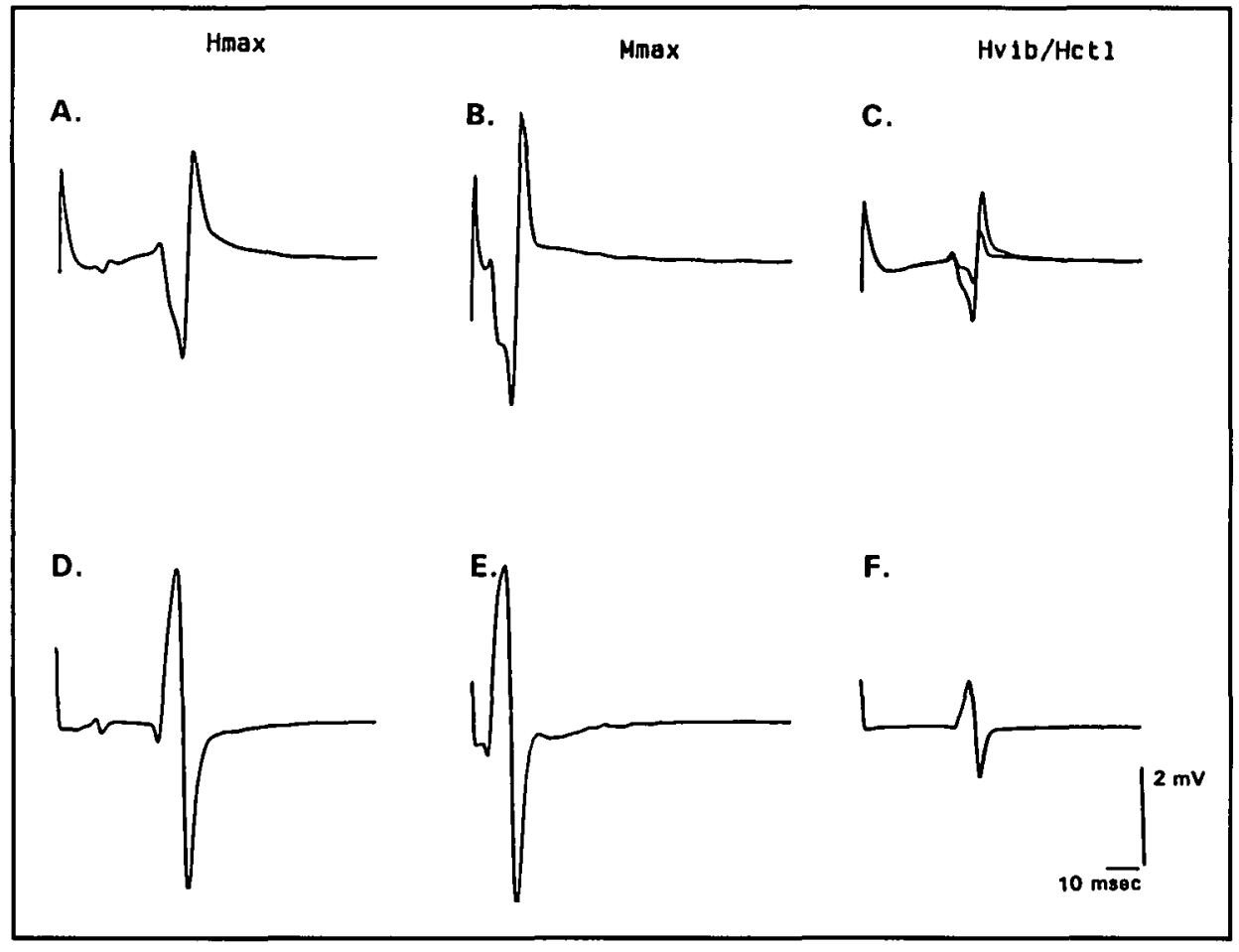

Figure 1 - Mean values $(n=10)$ of the maximal $H$ reflex (Hmax; $A$ \& $D$ ), maximal $M$ response (Mmax; $B$ \& $E$ ). and vibratory inhibition of the $H$ reflex (Hvib superimposed on $\mathrm{HCl} ; \mathrm{C} \& \mathrm{~F}$ ) in two hemiparetic subjects with mild $(\boldsymbol{A}-\boldsymbol{C})$ and severe $(\boldsymbol{D}-\boldsymbol{F})$ spasticity. For these subjects, the H/M ratios were $65.9 \%$ and 90.0\%, while the $\mathrm{Hvib} / \mathrm{Hct}$ ratios were $40.0 \%$ and $64.4 \%$ respectively. 


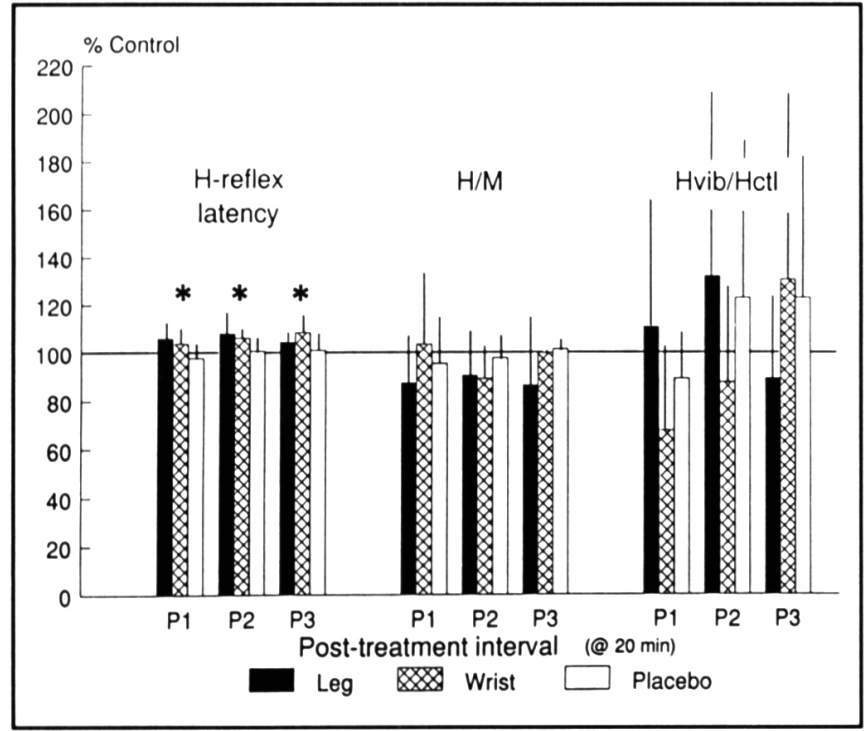

Figure 2 - Histograms of the means and standard deviations of poststimulation changes in $H$ reflex latencies (left), $H / M$ ratios (middle). and Hvib/Hctl ratios (right) for each of the three treatment procedures. Solid bars denote TENS treatment to the common peroneal nerve of the leg. Hatched bars represent TENS treatment to the contralateral wrist. Open bars indicate placebo stimulation to the leg. Post-stimulus changes at three 20 min intervals (P1, P2, P3) are expressed as percentages of the control values. Compared to placebo stimulation, the mean $H$ reflex latencies over the three 20 min intervals were significantly prolonged after TENS to either site $(p<0.02$; asterisks).

stimulation, 20, 40, and 60 minutes after 45 minutes of TENS stimulation to the skin overlying the common peroneal nerve. Note the consistency of the stretch perturbations across the trials. The prolongation of stretch reflex latencies is clearly seen in this example, as an increased distance from the vertical line placed at the onset of the control response in Figure 3A. To examine the group effects, individual post-treatment data were expressed as percentages of each subject's own control values. Figure 4 shows the mean percentages of these latency changes in the three $20 \mathrm{~min}$ intervals after TENS or placebo stimulation for all of the subjects examined. The mean values pooled from all three post-stimulation intervals for stretch reflex latencies were $110.5 \pm 4.5 \%$ for TENS applied to the contralateral wrist, and $109.8 \pm 9.2 \%$ for TENS applied to the ipsilateral leg. These were significantly longer than the value obtained following placebo stimulation $(90.8 \pm 7.7 \%$; $<<0.05)$. Interestingly, the increase in stretch reflex latencies was evident for at least 60 min post-TENS stimulation.

TENS had no consistent effects on clinical spasticity, stretch reflex durations or stretch-evoked clonus. However, one would expect a relationship between $\mathrm{H}$ and stretch reflex latency and their corresponding amplitude or area measures since, even without changes in reflex gain, a prolongation of reflex latency could result in a decrease in the magnitude of the response. TENS stimulation resulted in a decreased $\mathrm{H}$ reflex amplitude or stretch reflex area in a constant proportion of subjects $(50 \%)$. The relationship between reflex latency and magnitude in each subject is shown in Figure 5 for those subjects receiving TENS to the leg (A, B: closed circles), TENS to the wrist (A, B: open circles) and placebo (C, D: squares). Figure 5 ( $A$ and $B$ ) demon-

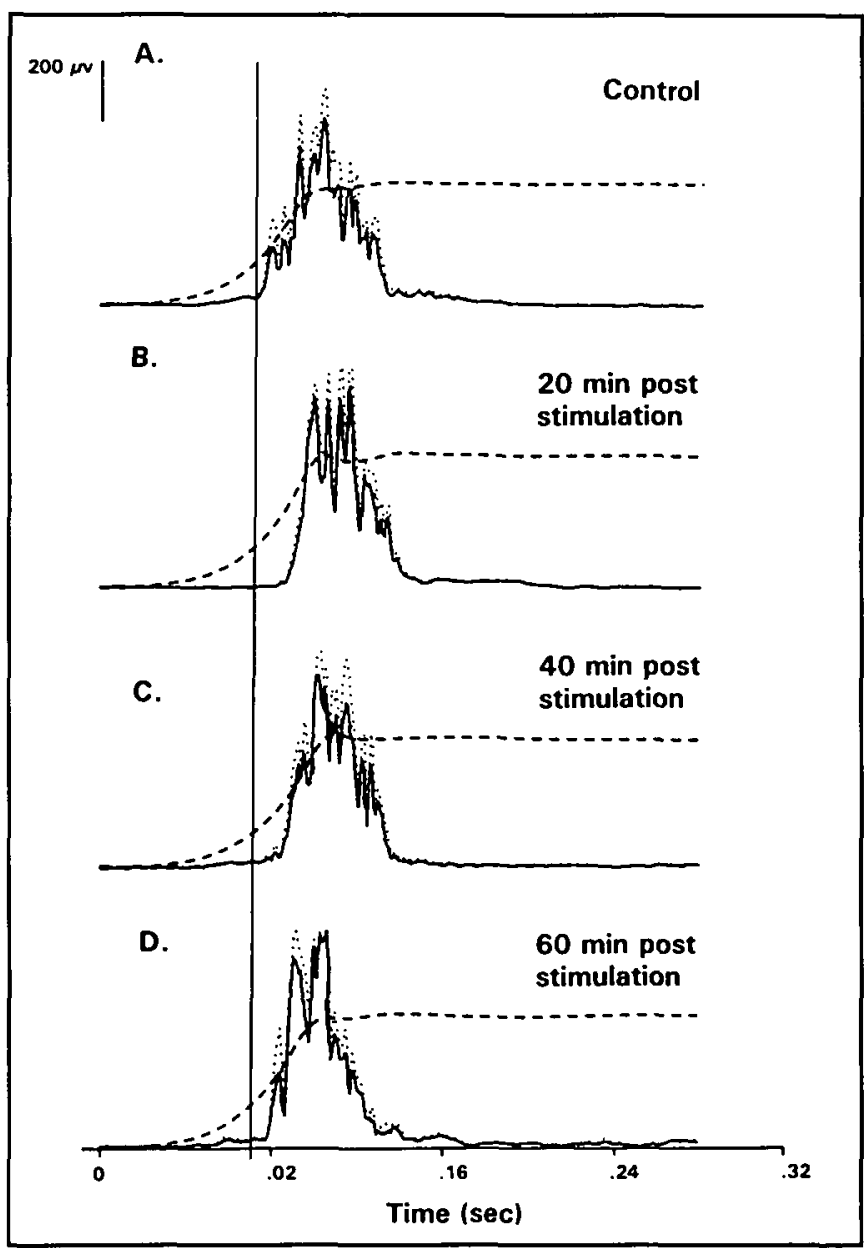

Figure $3-$ Mean $(n=10)$ soleus stretch reflexes in one subject with moderate spasticity $(\boldsymbol{A})$ before. $(\boldsymbol{B}) 20,(\boldsymbol{C}) 40$ and $(\boldsymbol{D}) 60 \mathrm{~min}$ after. $45 \mathrm{~min}$ of TENS to the common peroneal nerve. Stretch reflex responses are shown on the same time scale as the ankle displace. ment (dashed lines). Vertical line indicates the control stretch reflex latency. The prolongation of onset latencies in each post-stimulus time interval is clearly seen as an increased distance from this line.

strates that the predominant effect of TENS stimulation was a prolongation of reflex latency (in approximately $76 \%$ of the $\mathrm{H}$ reflex responses in $\mathrm{A}$; and in $78 \%$ of the stretch reflex responses in $B$ ) and that this was accompanied by a decrease in the reflex amplitude in only $53 \%$ and $48 \%$ of the responses respectively. In contrast, placebo stimulation rarely resulted in a prolonged stretch reflex latency together with a decreased amplitude (Figure 5C and D).

\section{Discussion}

In our study, both $\mathbf{H}$ (Figure 2) and stretch reflex latencies (Figures 3 and 4 ) showed a significant increase, by $5.7 \%$ to $10.5 \%$ respectively, following $45 \mathrm{~min}$ of low-threshold afferent conditioning. Of particular interest was that the increase in latency measures was equally evident after both segmentally and heterosegmentally applied TENS, but not after placebo stimulation (Figures 2 and 4). Furthermore, the effect generally outlasted the period of stimulation for at least $60 \mathrm{~min}$. 
Table 2. Effects of 45 min of TENS to the Common Peroneal Nerve (CPN Stimulation) or to the Median Nerve at the Contralateral Wrist (Wrist Stimulation) on Soleus Stretch Reflex Latencies (ms) 20, 40 and $60 \mathrm{~min}$ After the End of Stimulation

\begin{tabular}{|c|c|c|c|c|c|c|c|c|c|}
\hline \multicolumn{5}{|c|}{ CPN Stimulation } & \multicolumn{5}{|c|}{ Wrist Stimulation } \\
\hline $\mathbf{S}$ & Control & $20 \mathrm{~min}$ & $40 \mathrm{~min}$ & $60 \mathrm{~min}$ & $\mathbf{S}$ & Control & $20 \mathrm{~min}$ & $40 \mathrm{~min}$ & $60 \mathrm{~min}$ \\
\hline 1 & 34.8 & 39.5 & 43.7 & 51.8 & 1 & 25.8 & 27.4 & 31.4 & 41.0 \\
\hline 7 & 37.6 & 42.2 & 33.6 & 48.3 & 4 & 38.9 & 50.0 & 52.1 & 39.1 \\
\hline 9 & 38.6 & 47.0 & 45.1 & 43.0 & 7 & 25.6 & 30.8 & 30.3 & 26.0 \\
\hline S.D. & 9.2 & 6.1 & 11.5 & 11.3 & & 9.3 & 11.9 & 11.3 & 8.2 \\
\hline 3 & 30.1 & 26.0 & - & - & 5 & 50.6 & 49.5 & 55.9 & 41.2 \\
\hline 4 & 70.5 & 62.2 & 66.1 & 68.4 & 10 & 28.2 & 30.4 & 28.0 & 28.1 \\
\hline 5 & 45.0 & 41.7 & 43.2 & 44.3 & & & & & \\
\hline 6 & 52.2 & 56.4 & 42.8 & - & & & & & \\
\hline
\end{tabular}

$" p<0.05$

A limited range of latency values has been reported in the largely monosynaptic $\mathrm{H}$ reflex and the mono- and polysynaptic stretch reflex. ${ }^{41}$ For instance, monosynaptic la EPSP latencies range from 0.4 to $2.0 \mathrm{~ms}^{41}$ In another monosynaptic pathway, Feldman and Orlovsky ${ }^{42}$ recorded from interneurons mediating

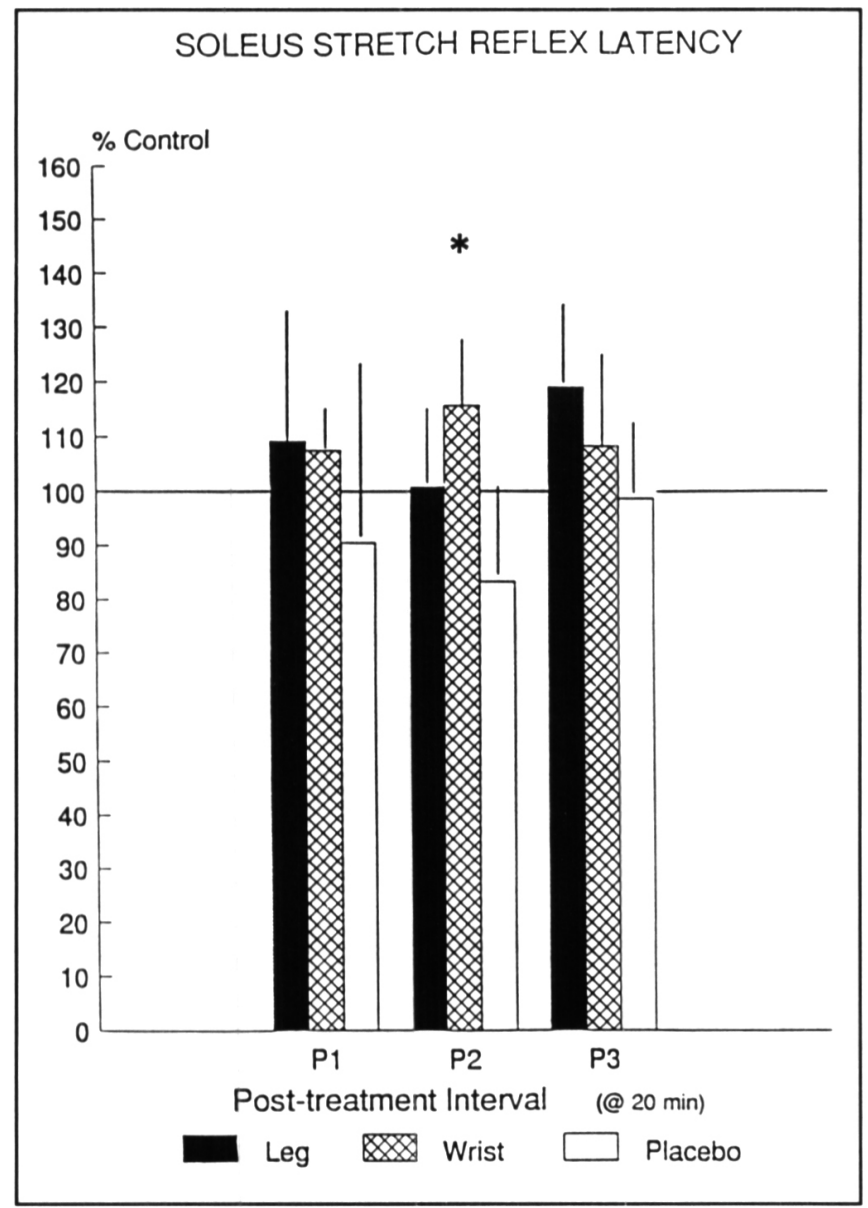

Ia reciprocal inhibition and showed that the latency of the la interneuronal spike evoked by stimulation of la afferents was modulated by the phase of locomotion in mesencephalic cats in the order of approximately $1-3 \mathrm{~ms}$ (see Figure 7 from ${ }^{42}$ ). In man, the maximal change in the central delay at the la- $\alpha$ motoneuronal synapse has been estimated as $0.4 \mathrm{~ms}$ after facilitatory and $0.9 \mathrm{~ms}$ after inhibitory conditioning of the soleus $\mathrm{H}$ reflex. ${ }^{43}$ In addition, the rise time of the induced change in excitability of the motoneuronal pool following $\mathrm{H}$ reflex and stretch (tendon tap) stimulation, estimated by evoking post-stimulus time histograms to electrical stimulation, ${ }^{40}$ ranged from 4.1 to $5.1 \mathrm{~ms}$ for electrically and 7.7 to $14.9 \mathrm{~ms}$ for mechanically evoked reflexes. Thus, our values for the prolongation of $\mathrm{H}$ (means $=1.7$ and $2.2 \mathrm{~ms}$ ) and stretch (means $=5.0$ and $6.4 \mathrm{~ms}$ ) reflex latencies can be accounted for by changes in motoneuronal threshold excitability.

Despite its effect on reflex latencies, TENS did not have statistically significant effects on all reflex magnitude measures. However, examination of Figure 5 shows that there was a strong tendency towards decreased reflex magnitudes concurrently with reflex latencies and this effect was significant $(p<0.05)$ at least for the $\mathrm{H}$ reflex following TENS to the wrist (Figure 5A). It is possible that some of the variability in $\mathrm{H}$ reflex amplitudes may have been attributed to fluctuations in baseline EMG excitability, ${ }^{44}$ but this was unlikely since our reflexes were evoked at rest with practically no initial EMG activity (see Figure 1). The lack of a statistically significant decrease in stretch reflex areas can be explained by the polysynaptic nature of the response. Since stretch reflex areas were measured over a

Figure 4-Histograms of the means and standard deviations of soleus stretch reflex onset latencies in each $20 \mathrm{~min}$ interval for each treatment procedure for all the subjects tested. Legends are the same as for Figure 2. Note that, in contrast to placebo stimulation. TENS applied to the leg or wrist significantly prolonged stretch refle. latencies $(p<0.05)$. 

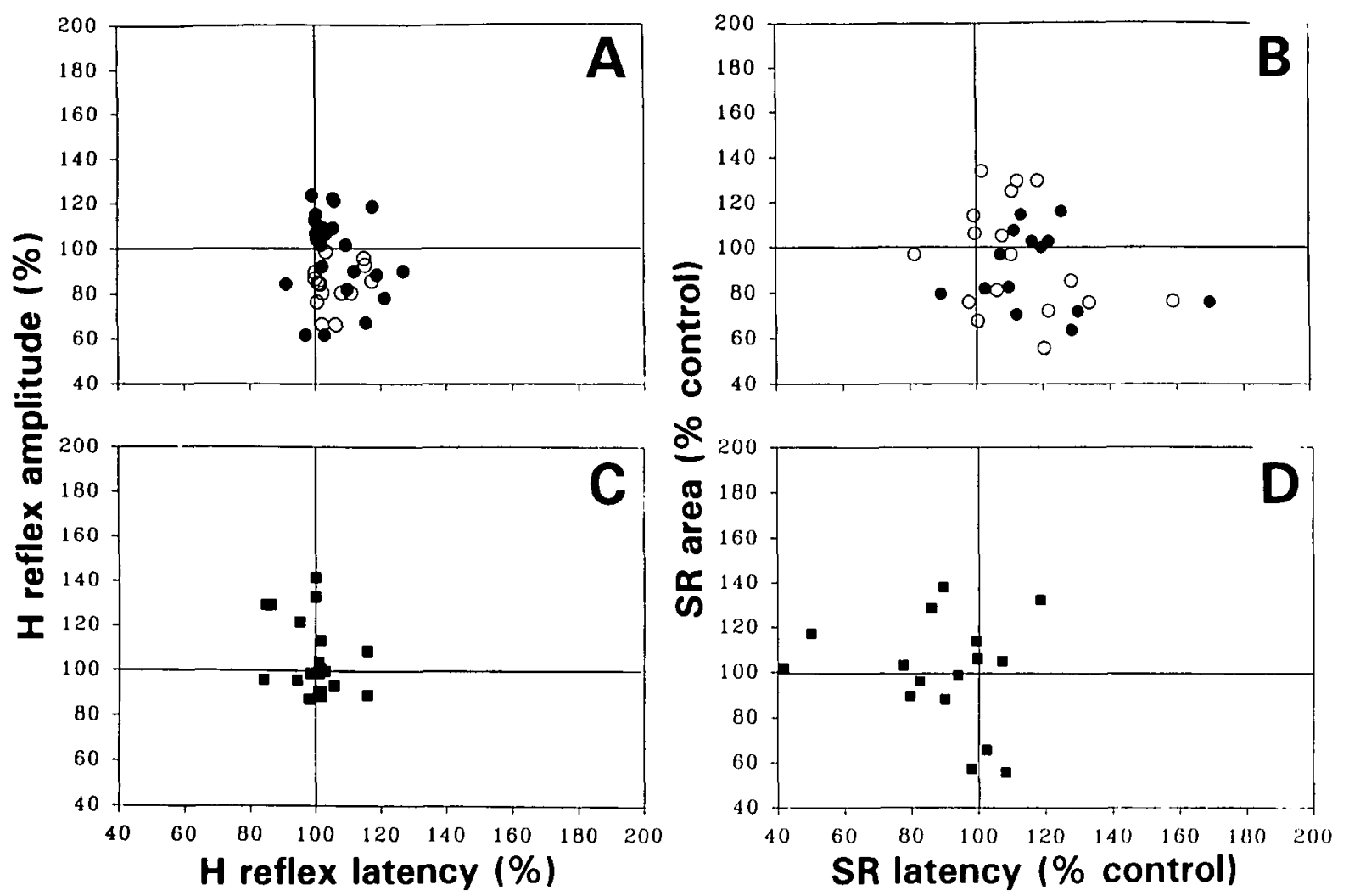

Figure 5-Relationship between $H$ and stretch reflex $(S R)$ latency and their respective amplinude or area values for the three types of stimulation. Results of TENS stimulation to the leg (closed circles) and to the wrist (open circles) are shown in A for the H reflex and in B for the SR. Results of placebo stimulation are shown by squares in $C$ for the $H$ reflex and in $D$ for the $S R$. Values were normalized by expressing them as the change in individual latency or magniude scores following stimulation in each of the three post-stimulation time periods compared to the pre-stimulation control score for each subject.

fixed $150 \mathrm{~ms}$ window following response onset which included both mono- and polysynaptic components, a small decrease in the monosynaptic segment of the reflex may not have been evident. Thus, our findings do not rule out the possibility of concomitant changes in the latency and amplitude of the monosynaptic component of the stretch reflex.

Although SR latencies following TENS were significantly prolonged in some subjects compared to control values (Table 2 ), the group effects were only statistically significant when compared to those following placebo stimulation. The latter can be explained by increased activity in polysynaptic reflex pathways with repetitive stretch perturbations over the long testing period $(105 \mathrm{~min})$, as demonstrated by the tendency of the latencies to decrease following placebo stimulation $(90.8 \pm 7.7 \%$ of control values, see Figure 4). Stretch sensitization of muscle spindles from finger extensor muscles in normal subjects has been demonstrated. ${ }^{45}$ However, the possibility of similar sensitization of muscle spindles in spastic ankle extensors following repetitive stretching remains to be investigated. In any case, the fact that an increase rather than decrease in latencies was evident after 45 min of TENS, as compared with placebo stimulation, suggested that it may have been the TENS stimulation itself that led to a decrease in motoneuronal excitability.

\section{Nature of Modulating Input and Possible Inhibitory Mechanisms}

Low intensity, high frequency TENS activates mainly large diameter $(A \alpha \beta)$ sensory afferent fibres. ${ }^{19}$ Since the same TENS parameters were used in this study and the stimulation evoked neither pain nor a motor response, similar afferents may have been involved in mediating the observed ipsilateral segmental and contralateral heterosegmental effects.

The immediate effects of remote, heterosegmental transcutaneous electrical conditioning of low-threshold afferents on lower limb stretch reflexes in hemiparetic subjects have not been previously described. On the other hand, Walker ${ }^{46}$ did observe a prolonged suppression of ankle clonus in multiple sclerosis patients, following one hour of subcutaneous stimulation of the contralateral radial/median nerve with implanted electrodes. In intact rats, a gradual enhancement of inhibition in spinal lumbar interneurons has been reported following repeated electrical cutaneous conditioning of the ipsilateral hindlimb. ${ }^{47}$ In that study, the inhibition outlasted the stimulation from $0.5 \mathrm{sec}$ to $7 \mathrm{~min}$ in intact but not spinal rats, suggesting that the development of inhibition depended on descending influences.

Although both segmental and heterosegmental stimulation affected lower limb $\mathrm{H}$ and stretch reflex latency values in a 
similar direction (Figures 2 and 4), the temporal pattern of the latency shift in the three $20 \mathrm{~min}$ time periods after TENS to the leg did not parallel those following TENS to the wrist. Hence, different mechanisms may have been at play. It is not likely that the observed effects can be ascribed purely to segmental mechanisms, but segmental reciprocal mechanisms may have predominated following the ipsilateral stimulation.

It is also possible that, low-threshold afferent stimulation could have decreased stretch reflex excitability via activation of descending pathways acting on reciprocal inhibitory mechanisms and/or propriospinal inhibitory pathways. A net decrease of thresholds, but not stiffness or magnitude of stretch reflexes in ankle extensor muscles ${ }^{48}$ has previously been reported following stimulation in specific areas of the brainstem of decerebrate cats (Dieter's nucleus, pyramidal tract, reticular forma(ion). The nature of such influences probably could not be attributed to presynaptic inhibitory mechanisms via la afferent terminals, since both segmental and heterosegmental afferent conditioning had no significant effect on the Hvib/Hctl ratios in our subjects (Figure 2). Vibratory inhibition of the $\mathrm{H}$ reflex is believed to be partially mediated by presynaptic inhibition of the Ia terminals involved in the presumed monosynaptic stretch reflex arc. ${ }^{49.50}$ This finding is consistent with similar observations of insignificant effects on Hvib/Hctl ratios immediately following heterosegmental TENS in another group of spastic hemiparetic subjects. ${ }^{8}$ However, presynaptic inhibitory mechanisms from non-la interneurons cannot be ruled out.

Finally, the post-stimulation effect paralleled the prolonged suppression of flexion reflex previously found by Chan and Tsang, ${ }^{24}$ a phenomenon that has been attributed to the release of opioids, e.g., $\beta$-endorphin. ${ }^{25.52}$

\section{ACKNOWLEDGEMENTS}

The authors are grateful to Dr. A.G. Feldman for advice and comments on the manuscript. Thanks are extended to the patients and staff of the Lethbridge Rehabilitation Centre and the Rehabilitation Institute of Montreal, Montreal, Quebec.

This project was financed by a grant from McGill University, and the research laboratory by the Medical Research Council of Canada and the Fonds de la Recherche en Santé du Québec.

M. Levin was supported by a scholarship from the Fonds de la Recherche en Santé du Québec. Present address: Centre de Recherche, Institut de réadaptation de Montréal, 6300 Darlington, Montreal, Quebec, Canada H3S 2J4.

\section{REFERENCES}

1. Lance JW. Symposium synopsis. In: Feldman RG, Young RR, Koella WP eds. Spasticity: Disordered Motor Control. Chicago: Year Book 1980; 485-494.

2. Gilman S, Lieberman JS, Marco LA. Spinal mechanisms underlying the effects of unilateral ablation of areas 4 and 6 in monkeys. Brain 1974; 97: 49-64.

3. Hagbarth K-E, Wallin G, Löfstedt L. Muscle spindle responses to stretch in normal and spastic subjects. Scand $\mathbf{J}$ Rehabil Med 1973; 5: 156-159.

4. Hagbarth KE, Wallin G, Löfstedt L, et al. Muscle spindle activity in alternating tremor of parkinsonism and in clonus. J Neurol Neurosurg Psychiatry 1975; 39: 636-641.

5. Feldman AG. Functional tuning of the nervous system with control of movement or maintenance of a steady posture. II. Controllable parameters of the muscle. Biophysics 1966; 11: 565-578

6. Feldman AG. Once more on the equilibrium-point hypothesis $(\lambda$ model) of motor control. J Mot Behaviour 1986; 18: 17-54.
7. Ashby P, Verrier M. Neurophysiological changes in hemiplegia. Neurology 1976: 26: 1145-1151.

8. Hale JL, Chan CWY. The acute effects of conventional TENS in the management of spasticity. Physiother Can 1986; 38: (Suppl 5) 3.

9. Dimitrijevic MR, Nathan PW. Studies of spasticity in man. 3. Analysis of reflex activity evoked by noxious cutaneous stimulation. Brain 1968; 91: 349-368.

10. Dimitrijevic MR, Faganel J, Lehmkuhl D. et al. Motor control in man after partial or complete spinal cord injury. $l n$ : Desmedt JE, ed. Motor Control Mechanisms in Health and Disease. New York: Raven Press 1983; 915-926.

11. Dimitrijevic MR, Nathan PW. Studies of spasticity in man. 1. Some features of spasticity. Brain 1967; 90: 1-30.

12. Stefanovska A, Gros N, Vodovnik L. Rebersek S, AcimovicJanezic R. Chronic electrical stimulation for the modification of spasticity in hemiplegic patients. Scand J Rehab Med Suppl 1988: 17: 115-121.

13. Duchenne GB. De l'éléctrisation localisée et de son application à la pathologie et à la therapeutique. Paris: Baillière, 1855.

14. Levine MG, Knott, M, Kabat H. Relaxation of spasticity by electrical stimulation of antagonist muscles. Arch Phys Med 1952; 11 668-673.

15. Alfieri V. Electrical treatment of spasticity. Scand J Rehab Med 1982: 14: 177-182.

16. Vodovnik L, Bowman BR, Hufford P. Effects of electrical stimulitIion on spinal spasticity. Scand J Rehab Med 1984; 16:29-34.

17. Nashold BS, Friedman H. Dorsal column stimulation for control of pain. Preliminary report on 30 patients. J Neurosurg 1972: 36: 590-597.

18. Cook AW, Weinstein SD. Chronic dorsal column stimulation in multiple sclerosis. NY State J Med 1973; 73: 2863-2872.

19. Levin MF, Hui-Chan CWY. Conventional and acupuncture-like transcutaneous electrical nerve stimulation excite similar afferent fibers. Arch Phys Med Rehabil 1993; 74: 54-60.

20. Fredriksen TA, Bergmann S, Hesselberg JP, et al. Electrical stimulation in multiple sclerosis. Comparison of transcutaneous electrical stimulation and epidural spinal cord stimulation. Appl Neurophysiol 1986; 49: 4-24.

21. Levin MF, Hui-Chan CWY. Relief of hemiparetic spasticity by TENS is associated with improvement in reflex and voluntary motor functions. Electroencephalogr Clin Neurophysiol 1992; 85: $131-142$

22. Chapman CE, Ruegg DG, Wiesendanger M. Effects of dorsal cord stimulation on stretch reflexes. Brain Res 1983; 258:211-215.

23. Siegfried J, Krainick JU, Haas H, et al. Electrical spinal cord stimulation for spastic movement disorders. Appl Neurophysiol 1978: 41: 134-141

24. Hui-Chan CWY. Tsang H. Inhibition of the human flexion reflex by low intensity, high frequency transcutaneous electrical nerve stimulation (TENS) has a gradual onset and offset. Pain 1987: 28: $239-253$

25. Facchinetti $F$, Sandrini G, Petraglia $F$, et al. Concomitant increase in nociceptive flexion reflex threshold and plasma opioids following transcutaneous nerve stimulation. Pain 1984; 19: 295303.

26. Lee WA, Boughton A, Rymer WZ. Absence of stretch reflex gain enhancement in voluntarily activated spastic muscle. Exp Neurol 1987; 98: 317-335.

27. Powers RK, Marder-Meyer J, Rymer WZ. Quantitative relations between hypertonia and stretch reflex threshold in spastic hemiparesis. Ann Neurol 1988: 23: 115-124.

28. Levin MF, Chan CWY. Stretch reflex latency changes following repetitive reciprocal and hetero-segmental electrical stimulation in spastic hemiplegic subjects. Soc Neurosci Abstr 1989; 15: 916.

29. Ashworth B. Preliminary trial of carioproddal in multiple sclerosis. The Practitioner 1964; 192: 540-542.

30. Berardelli A, Sabra AF, Hallet M, et al. Stretch reflexes of triceps surae in patients with upper motor neuron syndromes. J Neurol Neurosurg Psychiatry 1983; 46: 54-60.

31. Hoffmann P. Uber die Beziehungen der Sehnenreflexe zur willkurlichen Bewegung und zum Tonus. $\mathrm{Z}$ Biol 1918; 68: 351. 370. 
32. Schieppati M. The Hoffmann reflex: a means of assessing spinal reflex excitability and its descending control in man. Prog Neurobiol 1987; 28: 345-376.

33. Desmedt JE, Godaux E. Mechanism of the vibration paradox: excitatory and inhibitory effects of tendon vibration on single soleus muscle motor units in man. J Physiol (Lond) 1978; 285: 197-207.

34. Robinson KL, McComas AJ, Belanger AY. Control of soleus motoneuron excitability during muscle stretch in man. $J$ Neurol Neurosurg Psychiatry 1982; 45: 698-704.

35. Inman VT. The joints of the ankle. Baltimore: Williams and Wilkins 1976

36. Hugon $M$. Methodology of the Hoffmann reflex in man. In: Desmedt JE, ed. New Developments in Electromyography and Clinical Neurophysiology. Basel: Karger 1973: 3; 277-293.

37. Meinck $H-M$. Facilitation and inhibition of the human $H$ reflex as a function of the amplitude of the control reflex. Electroencephlogr Clin Neurophysiol 1980; 48: 203-211.

38. Angel RW, Hofmann WW. The $\mathrm{H}$ reflex in normal, spastic, and rigid subjects. Arch Neurol 1963; 8: 591-596.

39. Levin MF, Hui-Chan CWY. Are $\mathrm{H}$ and stretch reflexes in hemiparesis reproducible and correlated with spasticity? J Neurol 1993; 240: 63-71.

40. Burke D, Gandevia SC, McKeon B. Monosynaptic and oligosynaptic contributions to human ankle jerk and H-reflex. J Neurophysiol 1984: 52: 435-448.

41. Burke RE. Composite nature of the monosynaptic excitatory post synaptic potential. J Neurophysiol 1967; 30: 1114-1136.

42. Feldman AG, Orlovsky GN. Activity of interneurons mediating reciprocal la inhibition during locomotion. Brain Res 1975; 81 : 181-194.
43. Abbruzzese M, Reni L. Favale E. Changes in central delay of soleus $\mathrm{H}$ reflex after facilitatory or inhibitory conditioning in humans. J Neurophysiol 199I; 65: 1598-1605.

44. Verrier M. Alterations in $\mathrm{H}$ reflex magnitude by variations in baseline EMG excitability. Electroencephalogr Clin Neurophysiol 1985; 60: 492-499.

45. Edin BB, Vallbo AB. Stretch sensitization of human muscle spindles. J Physiol (Lond) 1988; 400: 101-111.

46. Walker JB. Modulation of spasticity: prolonged suppression of a spinal reflex by electrical stimulation. Science 1982; 216: 203 204.

47. Macdonald JF, Pearson JF. Inhibition of spinal interneuronal activity by repeated cutaneous stimulation: a possible substrate of flexor reflex habituation. J Neurobiol 1979; 10: 79-92.

48. Feldman AG, Orlovsky GN. The influence of different descending systems on the tonic stretch reflex in the cat. Exp Neurol 1972; 37: $481-494$

49. Gillies JD, Lance JW, Neilson PD. et al. Presynaptic inhibition of the monosynaptic reflex by vibration. J Physiol (Lond) 1969; 205: 329-339.

50. Burke D, Hagbarth K-E, Lofstedt L, et al. The responses of human muscle spindle ending to vibration of non-contracting muscles. J Physiol (Lond) 1976; 261: 673-693.

51. Baldissera $F$, Hultborn $H$, Illert $M$. Integration in spinal neuronal systems. In: Brooks VB, ed. Handbook of Physiology, Sect. I: The Nervous System, Vol II, Part 1. Bethesda: Am Physiol Soc 1981: 509-596.

52. Salar G, Job I, Mingrino S, et al. Effect of transcutaneous electrotherapy on CSF: $\beta$-endorphin content in patients without pain problems. Pain 1981; 10: 169-172. 